\title{
Structure, organization, and functions of cellulose synthase complexes in higher plants
}

\author{
Reginaldo A. Festucci-Buselli ${ }^{*}$, Wagner C. Otoni ${ }^{1}$ and Chandrashekhar P. Joshi ${ }^{2}$ \\ ${ }^{1}$ Departamento de Biologia Vegetal, Laboratório de Cultura de Tecidos, BIOAGRO, Universidade Federal de Viçosa, \\ Viçosa 36570-000, MG, Brazil. ${ }^{2}$ Biotechnology Research Center, School of Forest Resources and Environmental \\ Science, Michigan Technological University, Houghton, Michigan 49931, USA. *Corresponding author: \\ rfestuccibuselli@hotmail.com.Phone: 55-31-3899-2930,Fax: 55-31-3899-2580
}

Received: 30 January 2007; Returned for revision: 26 April 2007; Accepted: 26 May 2007

\begin{abstract}
Annually, plants produce about 180 billion tons of cellulose making it the largest reservoir of organic carbon on Earth. Cellulose is a linear homopolymer of $\beta(1-4)$-linked glucose residues. The coordinated synthesis of glucose chains is orchestrated by specific plasma membrane-bound cellulose synthase complexes (CelS). The CelS is postulated to be composed of approximately 36 cellulose synthase (CESA) subunits. The CelS synthesizes 36 glucose chains in close proximity before they are further organized into microfibrils that are further associated with other cell wall polymers. The 36 glucose chains in a microfibril are stabilized by intra- and inter-hydrogen bonding which confer great stability on microfibrils. Several elementary microfibrils come together to form macrofibrils. Many CESA isoforms appear to be involved in the cellulose biosynthetic process and at least three types of CESA isoforms appear to be necessary for the functional organization of CelS in higher plants.
\end{abstract}

Key words: cellulose biosynthesis, cellulose synthase (CESA), cellulose synthase complex (CelS), microfibril

Estrutura, organização e funções dos complexos da sintase da celulose em plantas superiores: Anualmente, as plantas produzem aproximadamente 180 bilhões de toneladas de celulose, sendo o maior reservatório de carbono orgânico no planeta. A celulose é um homopolímero linear composto por resíduos de glicose unidos por meio de ligações $\beta(1-4)$. A síntese coordenada das cadeias de glicose é orquestrada por complexos específicos ligados à membrana plasmática (CelS). Postula-se que o CelS é composto por aproximadamente 36 subunidades da sintase da celulose (CESA). Cada CelS sintetiza 36 cadeias de glicose dispostas lado a lado antes de serem organizadas em microfibrilas, que são, posteriormente, associadas com outros polímeros da parede celular. As 36 cadeias de glicose presentes em uma microfibrila são estabilizadas por pontes de hidrogênio intra e inter-cadeias, conferindo grande estabilidade às microfibrilas. As microfibrilas elementares são dispostas lado a lado, permitindo a formação das macrofibrilas. Várias isoformas da CESA podem estar envolvidas no processo de biossíntese de celulose e, no mínimo, três tipos de isoformas da CESA podem ser necessárias para a organização funcional de cada CelS em plantas superiores.

Palavras-chave: biossíntese de celulose, complexo da sintase da celulose (CelS), microfibrilas, sintase da celulose (CESA)

\section{INTRODUCTION}

Cellulose is an outstanding commodity due to its abundance and distinctive structural properties. For example, its tension resistance is comparable to that of steel (Eckardt, 2003). Even though cellulose has great commercial value for the pulp, paper, and textile as well as chemical industries which use it to produce commercially important polymers, cellulose biosynthesis in trees is still not well understood. Due to the economical significance of tree cellulose for forest product industries, we have 
focused our attention in this review on cellulose biosynthesis in trees. Most of the recent findings concerning the molecular mechanism of cellulose biosynthesis in higher plants resulted from research in model herbaceous plants and fiber crops and have been reviewed recently (Somerville, 2006).

Cellulose is synthesized by cellulose synthase enzymes (CESAs) and is regarded as a major sink for atmospheric carbon in plants because it is the main component of the plant cell wall (Delmer and Haigler, 2002). Many plant cell walls of commercial importance are made up of three layers: middle lamellae, primary cell wall, and secondary cell wall. The secondary cell wall is further subdivided into three sub-layers called S1, S2, and S3. All the layers present in the cell wall have two phases: microfibrilar and matrix (Brett and Waldron, 1990). The microfibrilar phase, a crystalline phase, is composed of microfibrils of cellulose and the matrix phase, a noncrystalline phase, is composed of a variety of polysaccharides (pectins and hemicelluloses), proteins, and phenolic compounds (lignin, ferulic acid, coumaric acid, and others) (Brett and Waldron, 1990).

There is a definite distinction between chemical composition of the primary and secondary cell walls. The most remarkable one is concerning the quantities of cellulose and lignin. The amount of lignin in secondary cell walls of trees like Populus trichocarpa (poplar) is 19$21 \%$, whereas in the primary cell wall lignin is absent (Mellerowicz et al., 2001). The content of cellulose, expressed in dry weight, in the primary cell wall of poplars is $20-30 \%$, whereas in the secondary cell wall it is $40-50 \%$ (Mellerowicz et al., 2001). For instance, some clones of Eucalyptus grandis cultivated in Brazil have a cellulose content of $43.9-49.7 \%$ in the secondary cell wall (Gomide et al., 2005).

In some special cases, when the developing angiosperm wood is under tension stress, a gelatinous layer ( $\mathrm{G}$ layer) is formed instead of the S2 or S3 layer (Timell, 1969; Mellerowicz et al., 2001; Pilate et al., 2004). The $\mathrm{G}$ layer is composed almost exclusively of highly crystalline axially oriented microfibrils of cellulose. An increase of $10-20 \%$ in the cellulose content and a significant decrease in lignin content has been observed in tension wood in response to the deposition of the $G$ layer. Thus tension wood may represent an excellent system to study processes involved in cellulose biosynthesis (Wu et al., 2000; Pilate et al., 2004). For example, in Populus tremuloides (aspen), the coexpression of three CesAs, namely, PtrCesA1,

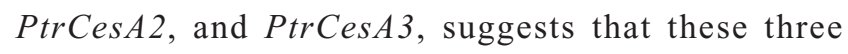
CesAs may be important for the biosynthesis of highly crystalline cellulose present in tension wood fibers (Bhandari et al., 2006). It has been reported that KORRIGAN (KOR), a type of cellulase, is involved in cellulose biosynthesis allowing proper formation of microfibrils of cellulose I (Delmer and Haigler, 2002; Molhoj et al., 2002). The aspen Kor gene (PtrKor) has been isolated and its expression pattern has been analyzed in aspen. Similar to three aspen CESAs, a high amount of PtrKOR protein was detected in developing xylem as well as on the upper side of the bent aspen stem in response to tension stress. In contrast, a very low amount of PtrKOR protein was detected on the opposite side of the bent stem experiencing compression stress (Bhandari et al., 2006).

In this review, we will discuss the process of cellulose biosynthesis. In addition, structural characteristics of cellulose and CESAs, as well as the structural, organizational, and functional features of CESA complexes (CelS) will be discussed.

\section{MOLECULAR AND SUPRAMOLECULAR FEATURES OF CELLULOSE}

Cellulose is a linear homopolymer made up of $\beta(1-4)$ linked glucose residues and the UDP-glucose molecule acts as substrate for cellulose biosynthesis. All alternate glucose residues in the same cellulose chain are rotated $180^{\circ}$ and are $\beta(1-4)$-linked by CESA isoforms. An anhydroglucose, one glucose residue, is a monomer of cellulose. The dimer, two glucose residues $\beta(1-4)$-linked, called cellobiose is the structural repetitive unit of the cellulose chain. The degree of polymerization is determined by the number of monomers which compose each cellulose chain (Brown et al., 1996; Delmer, 1999). Two different ending groups are found in each cellulose chain edge (Figure 1). At one end of each of the chains, a non-reducing group is present where a closed ring structure is found. A reducing group with both an aliphatic structure and a carbonyl group is found at the other end of the chains. The cellulose chain is thus a 


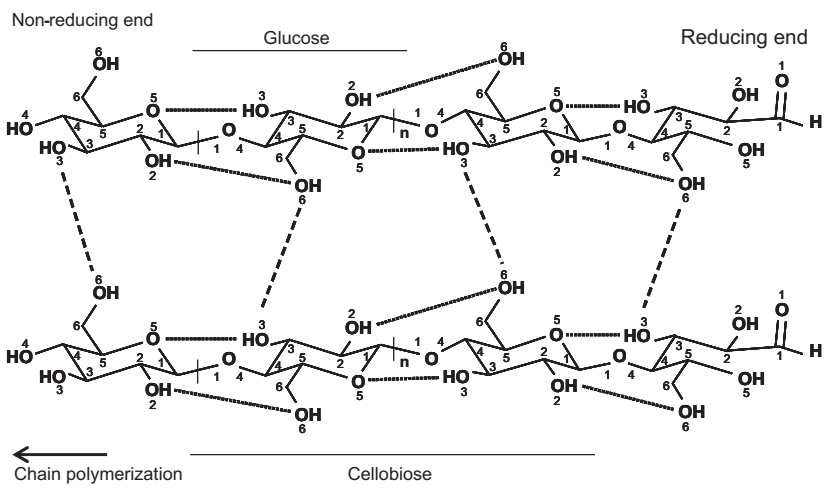

Figure 1. The structure and the inter- and intra-chain hydrogen bonding pattern in cellulose I. Dashed lines: inter-chain hydrogen bonding. Dotted lines: intra-chain hydrogen bonding.

polarized molecule. New glucose residues are added at the non-reducing end by CESAs allowing chain elongation (Koyama et al., 1997).

The $\beta(1-4)$ linkage between glucose residues, in contrast to the $\alpha(1-4)$ linkage as occurs in starch, confers cellulose with unique structural features. Cellulose is a water-insoluble polymer with a rigid linear structure. Controlled cellulose biosynthesis allows arrangement of extensive linear chains which can be aligned side-byside, creating fibers of great mechanical strength. As a consequence, tension resistance of cellulose is comparable to that of steel (Eckardt, 2003). In nature, cellulose is the main structural component of the cell wall and responsible for many of its distinctive traits.

Six different crystalline polymorphs of cellulose are known: cellulose I, II, III, III $_{\text {II }}$ IV $_{\mathrm{I}}$, and IV $_{\mathrm{II}}$. Cellulose I and II are found in nature. The others are obtained artificially by chemical or heat treatments. Cellulose I is the main form found in nature and it occurs as two allomorphs denominated $\mathrm{I} \alpha$ and $\mathrm{I} \beta$ (Figure 2). Higher plants synthesize both allomorphs, called cellulose I $\beta$ and $\mathrm{I} \alpha$ like chains. The cellulose I $\alpha$-like chain is conformationally similar to crystalline algal cellulose I $\alpha$, but is accommodated in a different hydrogen-bonding environment (Sturcova et al., 2004).

Cellulose II is the most crystalline thermodynamic stable form. It can also be obtained from cellulose I by two processes called regeneration and mercerization. Cellulose is found in amorphous form that is usually associated with cellulose I (O'Sullivan, 1997). Because
A

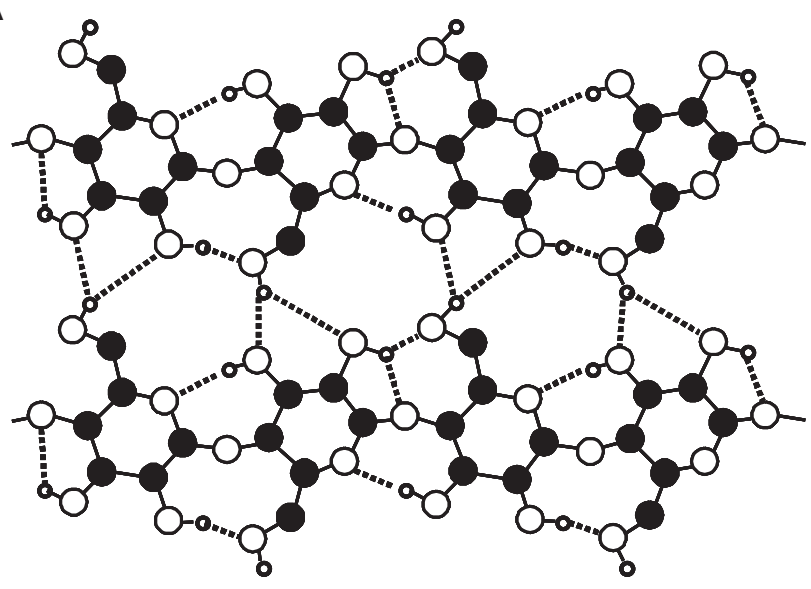

B

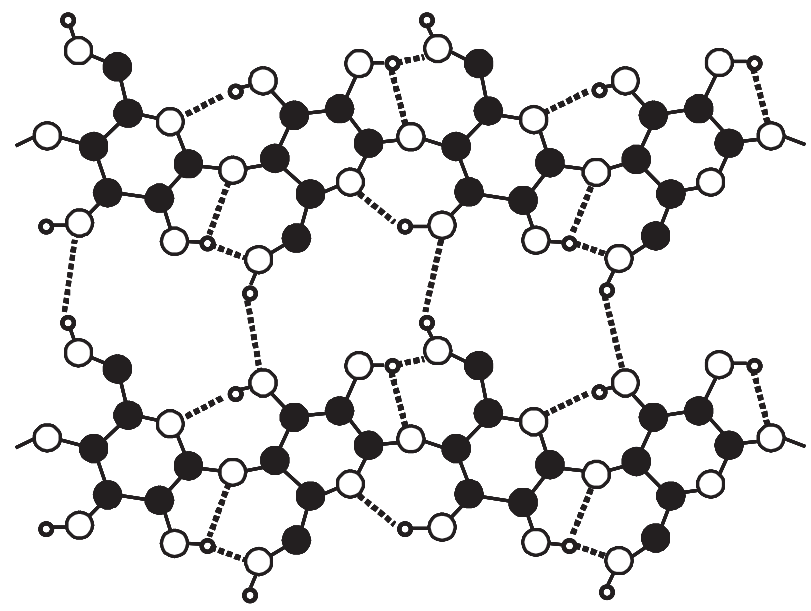

Figure 2. Hydrogen-bonding patterns in cellulose I $\alpha$ (A) and $\mathrm{I} \beta$ (B) based on the crystal structures of Nishiyama et al. (2002, 2003). Hydrogen bonds are represented by dotted lines. Note that cellulose I $\alpha$ and I $\beta$ show a different hydrogen-bonding pattern. Carbon $(\bullet)$, oxygen $(\mathbf{O})$, and deuterium atoms $(\mathbf{o})$. Reprinted with permission from Sturcova et al. (2004). Copyright (2006) American Chemical Society.

cellulose I and II are present in nature, we shall focus our attention on these forms in this review, but more specifically on cellulose I. The inter-chain hydrogen bonding pattern differs for the two forms. The O6-H-O3 inter-chain hydrogen bonding is dominant in cellulose I, whereas $\mathrm{O} 6-\mathrm{H}-\mathrm{O} 2$ is the main inter-chain hydrogen bonding in cellulose II. The $\mathrm{O} 3-\mathrm{H}-\mathrm{O} 5$ intra-chain hydrogen bonding which exists in both polymorphs (I and II) is responsible for the rigid and linear shape of each cellulose chain (Figure 1) (Langan et al., 2001; Nishiyama et al., 2002, 2003). 
The resolution of cellulose structure reveals that in I $\beta$ there are two conformationally distinct chains in a monocyclic unit cell (all glucosyl residues are identical except that they face alternately in opposite directions). In contrast, in I $\alpha$ there is one chain in a triclinic unit cell (alternate glucosyl residues differ slightly in conformation and hydrogen bonding) (Figure 3). The O2$\mathrm{H}-\mathrm{O} 6$ intra-chain bonding is present in both allomorphs I $\alpha$ and I $\beta$; however, it is shorter in I $\alpha$ (Nishiyama et al., 2002). The conformation of anhydroglucose residues and the $\beta(1-4)$ linkages are the molecular characteristics which distinguish cellulose I $\alpha$ and I $\beta$ (Kono et al., 2002). The $\mathrm{O} 2$ and $\mathrm{O} 6$ atoms show multiple possibilities of hydrogen bonding. This may be the reason why $\mathrm{O} 2$ and $\mathrm{O} 6$ are the most reactive of the hydroxyl groups on the crystalline surface of cellulose (Figure 1). Conversely, the $\mathrm{O} 3$ atoms are not reactive due to the strength of the intra-chain $\mathrm{O} 3$ $\mathrm{H}-\mathrm{O} 5$ bonding (Rowland and Howley, 1988). Cellulose I $\alpha$ is less stable than I $\beta$ and it can be converted into I $\beta$ by heating (Hardy and Sarko, 1996; Wada, 2002).
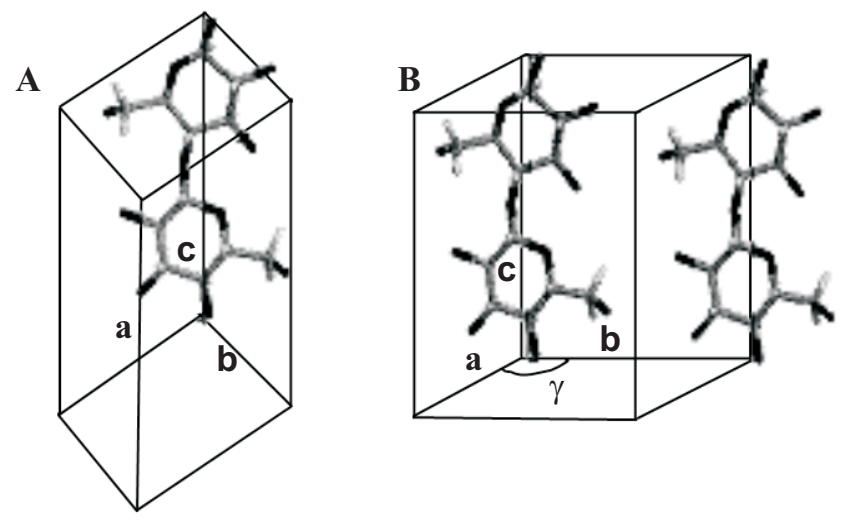

Figure 3. Schematic representation of mode of chain packing in the unit cell of cellulose. (A) Triclinic unit cell: cellulose I $\alpha$. (B) Monoclinic unit cell: cellulose I $\beta$. Monoclinic angle $\gamma$ is obtuse. Reprinted with permission from Koyama et al. (1997). Copyright (2006) The National Academy of Sciences of the United States of America.

\section{ELEMENTARY FIBRIL, MICROFIBRILS AND MACROFIBRILS OF CELLULOSE}

The cellulose microfibrils are structural units which compose the microfibrilar phase of each layer of cell wall. Theoretically, elementary fibrils are composed of only $\beta(1-4)$-linked glucose residues synthesized by the CESA complex (Ding and Himmel, 2006). Glucose chains are set parallel and aligned side-by-side in a specific crystalline arrangement. Microfibrils are thus composed of elementary fibrils that are further associated with noncellulosic polymers. Each cellulose microfibril has approximately 36 glucose chains. The glucose chains are stabilized by intra- and inter-hydrogen bonding which confers greater stability on microfibrils (Nishiyama et al., 2002, 2003). The degree of polymerization of cellulose chains is around 2,000-25,000 glucose residues (Brown et al., 1996). In aspen, the degree of polymerization of cellulose chains in the primary cell wall is approximately 4,200. In contrast, 9,200 glucose residues form cellulose chains in the secondary cell walls of aspen wood (Mellerowicz et al., 2001).

The coordinated synthesis of the glucose chains occurs in specific places in the plasma membrane where the CelS synthesizes glucose chains side-by-side before crystallization takes place. This process is highly organized and allows formation of cellulose I instead of cellulose II. Furthermore, it avoids the formation of noncrystalline cellulose I (Saxena and Brown, 2005). In many plants, cellulose microfibrils have $3 \mathrm{~nm}$ of diameter in the primary cell wall. In contrast, in the secondary cell wall, elementary microfibrils are put together side-by-side in a specific arrangement, allowing formation of macrofibrils (Delmer and Amor, 1995; Ding and Himmel, 2006). Macrofibrils are 5-10 nm in diameter (Brown et al., 1996; Jarvis, 2003). In some algae, microfibrils may have $20 \mathrm{~nm}$ of diameter (Jarvis, 2003); however, a much wider range in diameter of microfibrils, $10-68 \mathrm{~nm}$, is found in the algae Erythrocladia subintegra (Tsekos, 1999; Tsekos et al., 1999).

Recently, a microfibril structural model based on direct visualization of the primary cell wall of maize parenchyma cells was proposed by using atomic force microscopy (Ding and Himmel, 2006). According to this model, 36 glucose chains are distributed into three groups based on their location (Figure 4). The first group, comprising the center true-crystal core is composed of six glucose chains (Ch1-6), forming a hexagonal cross section. This group is considered truly crystalline. The second group encompasses chains directly associated with the crystal core and is composed of 12 subcrystalline chains (Ch7-18). Finally, the third group includes 18 subcrystalline or noncrystalline chains located on the surface of the crystal (Ch19-36). The 


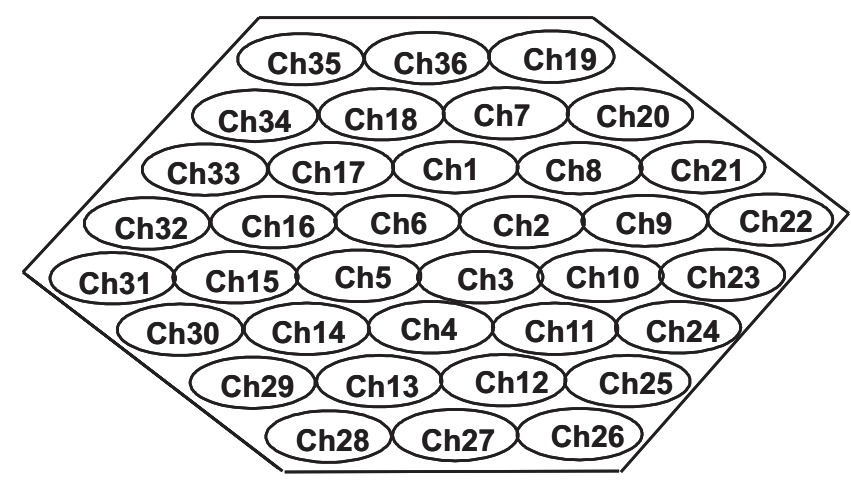

Figure 4. Cross-section of the 36-chain elementary fibril showing number of chains. Chains are numbered from $\mathrm{Ch} 1$ to $\mathrm{Ch} 36$ and categorized into three groups: group-C1 (Ch16) contains six true crystalline chains, group- $\mathrm{C} 2$ (Ch7-18) contains twelve subcrystalline chains, and group-C3 (Ch19-36) contains 18 subcrystalline or noncrystalline chains. Reprinted with permission from Ding and Himmel (2006). Copyright (2006) American Chemical Society.

groups 2 and 3 form protection and transition phases between the crystal core and later-deposited noncrystalline polymers. It is postulated that this model is structurally similar to the cellulose I $\beta$ model (Figures $2 \mathrm{~B}$ and $3 \mathrm{~B})$.

\section{CELLULOSE SYNTHASE COMPLEX (CelS)}

The CelS, usually called the terminal complex or rosette, is proposed to be composed of six subunits which are arranged in hexagonal symmetry. It is $25-30 \mathrm{~nm}$ in diameter (Mueller and Brown, 1980; Delmer, 1999). Each subunit of CelS has six CESA isoforms which produce six glucan chains (Brown and Saxena, 2000). The CelS is thus theoretically composed of 36 CESAs. At least three types of CESA isoforms, called $\alpha_{1}, \alpha_{2}$, and $\beta$, may be necessary for the spontaneous arrangement of CESAs in each CelS (Doblin et al., 2002; Ding and Himmel, 2006). Consistent with this hypothesis, different types of CesA isoforms have been found to be coexpressed in Arabidopsis thaliana: AtCesA4, AtCesA7, and AtCesA8 (Taylor et al., 2003); barley: HvCesA1, HvCesA2, and HvCesA6 (Burton et al., 2004); poplar: PtrCesA1, PtrCesA2, and PtrCesA3 (Joshi et al., 2004; Bhandari et al., 2006); and rice: OsCesA4, OsCesA7, and OsCesA9 (Tanaka et al., 2003). However, expression of several CesA isoforms in the same cell does not necessarily indicate that they interact and are part of the same CelS. According to the expression pattern and functional redundancy, three situations are possible: (i) different isoforms are expressed in different cells; (ii) different isoforms are expressed in the same cell, but they are functionally redundant; and (iii) different isoforms are expressed in the same cell, but they are essential and are not redundant (Perrin, 2001).

Several models have been proposed to explain interactions among CESA isoforms, allowing proper formation of CelS (Scheible et al., 2001; Doblin et al., 2002; Joshi, 2003a). These models are based on the hypothesis that one elementary fibril is composed of 36 glucose chains, which are synthesized by 36 CESA isoforms arranged in a planar configuration in the plasma membrane (Delmer, 1999; Kimura et al., 1999; Scheible et al., 2001). The number of CESA isoforms and the type of interactions among them are the distinctive features of each model. In the model proposed by Ding and Himmel (2006), 36 CESA isoforms are assembled into rosettes located in the plasma membrane (Figure 5). Each CelS has six identical subunits composed of six CESA isoforms: one $\alpha_{1}$, two $\alpha_{2}$, and three $\beta$ (Figure 5A). Three types of protein-protein interactions $\left(\beta-\beta, \alpha_{1}-\beta\right.$, and $\left.\alpha_{2}-\beta\right)$ may be involved in the spontaneous assembly of CelS (Figure 5B). Several CelS arranged in the plasma membrane may form a honeycomb array (Figure 5C). The honeycomb array structure could synthesize a great number of elementary fibrils to form a macrofibril.

\section{CeIS IS COMPOSED OF CESA ISOFORMS THAT ARE ENCODED BY Ces $A$ GENES}

Several experiments were successfully conducted to suggest that CelS are made up of multiple CESA isoforms that are encoded by distinct $C e s A$ genes.

(i) CelS (rosette) is associated with biogenesis of microfibrils of cellulose: The discovery of the cotton Ces $A$ genes encoding potential catalytic subunits of CelS revealed the involvement of CelS in biosynthesis of microfibrils of cellulose. The identification of potential components of the plant CelS complex was achieved by a molecular approach. Two cDNA clones GhCESA1 and GhCESA2 were identified in cotton fiber enriched in cellulose (Pear et al., 1996). These cDNAs encoded 


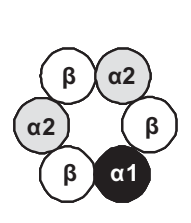

A. CESA isoforms
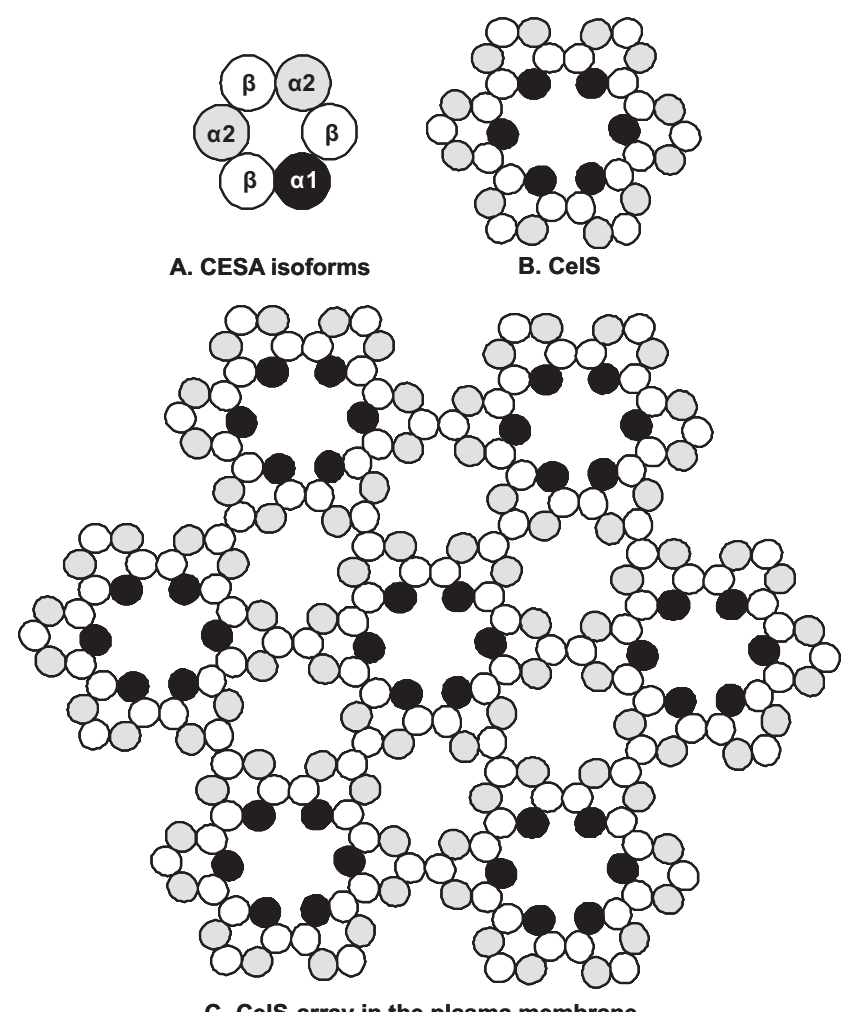

C. CelS array in the plasma membrane

Figure 5. Schematic model structure of the cellulose synthases complex (rosettes) in higher plants. Reprinted with permission from Ding and Himmel (2006). Copyright (2006) American Chemical Society.

proteins with some similarity to the bacterial CESA proteins. Besides, sequence analysis revealed existence of the motif D, D, D, QxxRW (motifs indicative of processive glycosyltransferase) (Saxena and Brown, 1995). It was shown that GhCESA1 was able to bind to the substrate UDP-glucose and the expression patterns of GhCesA1 and GhCesA2 were tightly linked with the timing of cellulose biosynthesis (Pear et al., 1996). Collectively, these findings supported the hypothesis that GhCesAl and GhCesA2 encoded potential catalytic subunits of CelS which may be associated with biogenesis of microfibrils of cellulose (Doblin et al., 2002).

(ii) Proper assembly of CelS depends on protein encoded by AtCesA 1: To demonstrate that rosettes are made up of intact CESAs, the temperature-sensitive mutant $r s w 1$ was analyzed (Arioli et al., 1998). It displayed disassembly of CelS (or rosettes) in the plasma membrane, altered cellulose crystallinity (or production of non-crystalline cellulose), and interrupted morphogenesis. This mutant showed at ambient temperature $\left(18^{\circ} \mathrm{C}\right)$ regular assembly of CelS. When mutant plants were exposed to high temperatures $\left(31^{\circ} \mathrm{C}\right)$, CelS was not correctly assembled. The gene responsible for this phenotype was isolated by map-based cloning. Sequence analysis revealed that the amino acid $\mathrm{Ala}^{549}$ in the wild-type was substituted by $\mathrm{Val}^{549}$ in $r s w 1$ and that this gene encoded the catalytic subunit of CESA based on homology with cotton CESAs (Pear et al., 1996). Reverse genetics experiments were used to show that the cloned wild-type AtCesAl gene complements the rsw1 mutant. Therefore, RSW1 locus encodes the catalytic subunit of CESA (AtCESA1) which is involved in CelS assembly. It was proposed that the $r s w 1$ mutant allele interrupts assembly of glucan chains into microfibrils. In the mutant, at the restrictive temperature, CelS is not properly assembled suggesting that the proper assembly of CelS depends on the presence of wild-type AtCesAl (Arioli et al., 1998).

(iii) CESA is one of the components of CelS: To show that CESA is a component of CelS, an indirect method was employed using polyclonal antisera produced against the catalytic region of cotton CESA (Kimura et al., 1999). The primary antibody was used to recognize the CESA present in the plasma membrane-localized CelS. Antirabbit secondary antibodies coupled to $10 \mathrm{~nm}$ colloidal gold were used to recognize CESAs. Once the dimension of the primary-secondary antibody complex was known $(27.2 \mathrm{~nm})$, it was labeled for visualization of the CESA using transmission electron microscopy. The technique of freeze-fracture of the plasma membrane was employed. After fracture, the rosettes are present in the leaflet section of the plasma membrane bilayer that is nearest the cytoplasm (the P-fracture face). The CESA antibodies specifically recognized CelS on the P-fracture face. Gold particles were observed directly over or close to CelS. It suggested that CESA is a component of CelS (Kimura et al., 1999).

(iv) AtCESA4, AtCESA7, and AtCESA8 are co-localized in xylem cells and show interactions: To demonstrate that three secondary wall-associated CESAs might be involved in rosette assembly, polyclonal antisera were raised against three distinct secondary wall-associated 
Arabidopsis CESAs, namely, AtCESA4, AtCESA7, and AtCESA8 (Taylor et al., 2003). Tissue prints of the stem sections were hybridized with AtCESA4, AtCESA7, and AtCESA8 antibodies, indicating that the labeling in the xylem and interfascicular region in tissue prints was caused by specific recognition of AtCESA4, AtCESA7, and AtCESA8 proteins. It suggested that these genes are co-expressed in the same cells although no cellular details were visible. The next step was to verify if there is actual interaction between them. To accomplish this, a histidine tag was fused at the amino terminal of AtCESA4, AtCESA7, and AtCESA8 proteins. Such a tag allows purification of tagged protein on a Ni column and verification of interacting proteins with tagged protein can be done using Western blot provided antibodies for the interacting proteins are available. Mutant plants were transformed with the respective constructs carrying the wild-type AtCesA gene and the proteins were extracted from the transgenic stems. Successful complementation of the mutant with such a construct suggested that Histag did not interfere with the biological function of CESA. The purification of AtCESA4, AtCESA7, and AtCESA8 and interacting proteins was performed by using immobilized metal affinity chromatography. These proteins were resolved by polyacrylamide gel electrophoresis and transferred to a nitrocellulose membrane and probed with AtCESA4, AtCESA7, or AtCESA8 antibodies. According to the data, there are positive interactions among them and consequently they can be part of the same complex (Taylor et al., 2003).

Taken together, these findings support that CelS is at least composed of diverse CESA isoforms encoded by distinct CesA genes. Read and Bacic (2002) have further suggested that there are other non-CESA components of rosettes but so far no other proteins have been proven to be part of the rosettes.

\section{ASSEMBLY OF CelS AT THE PLASMA MEMBRANE AND BIOSYNTHESIS OF CELLULOSE}

The cellulose is deposited on the external surface of each plant cell. It cannot be synthesized inside the cells because it is a water-insoluble polymer with a rigid linear structure. To accomplish this, the CelS needs to be organized throughout the plasma membrane, forming a channel through which UDP-glucose (a soluble molecule) can pass from the cytoplasm, and be further converted into cellulose (an insoluble polymer) by the action of CESA enzymes. Therefore, it is crucial that CelS is accurately assembled in the plasma membrane.

It has been postulated that two phases of assembly of the CESAs are required (Saxena and Brown, 2005). In the first phase, probably within the cytoplasmatic domain of CelS, three different homodimers could be folded, forming a linear array with six particles. A distinctive CESA may be present in each dimer. In the second phase, apparently in the endoplasmic reticulum and the Golgi apparatus, the linear arrays may be arranged in a rosette with a six-fold symmetry. The assembled CelS may then be transported to the plasma membrane for its activation and subsequent cellulose microfibril synthesis (Haigler and Brown, 1986). Two steps may be necessary for cellulose crystallization. The first one could be formation of monomolecular glucan sheets. Glucan sheets may be folded side-by-side by van der Waals forces inside of CelS rows. In the second step, six separate glucan chain sheets could pass through the CelS orifice and may then be hydrogenbonded into the crystalline cellulose I microfibril.

In plants, besides CESAs, at least $\mathrm{P}$-sucrose synthase (P-SUSY), which is associated with the plasma membrane, and membrane-bound endo-1,4- $\beta$-D-glucanase (KOR) are involved in cellulose biosynthesis (Read and Bacic, 2002). The formation of CelS takes place with the coordinate expression of CesAs. Even though firm evidence is not available, it is hypothesized that once the CelS is properly folded and assembled in the plasma membrane, P-SUSY might be converting sucrose into UDP-glucose and fructose. The released UDP is recycled, becoming available again to SUSY for formation of UDPglucose (Haigler et al., 2001). The UDP-glucose molecules are then $\beta(1-4)$-linked by CESAs. The polymerization of glucose chains, assembling, processing, and formation of microfibrils of cellulose I seem to be a highly synchronized process catalyzed by CelS. During the conversion of glucose chains into the microfibril of cellulose $\mathrm{I}$, it has been suggested that monitoring and editing of the microfibril of cellulose I takes place involving KOR, which is associated with the plasma membrane (Delmer and Haigler, 2002; Molhoj et al., 2002). It has been shown that the deposition of cellulose involves regulated intracellular traffic of KOR1 (Robert et al., 2005). 


\section{STRUCTURAL FEATURES OF CESA PROTEINS}

The genes encoding CESAs were first discovered in Acetobacter xylinum (Saxena et al., 1990; Wong et al., 1990). After six years, the first plant CesAs, GhCesAl and GhCesA2 were identified in cotton (Pear et al., 1996). Since then, CesAs have been identified in several species. Arabidopsis thaliana has at least ten CesAs which are denominated AtCesA1-10 (Richmond and Somerville, 2000), following the proposed nomenclature for the genes involved in cellulose synthesis (Delmer, 1999). Nine CesA genes were identified in maize (Holland et al., 2000). In aspen, seven CesA members were extensively characterized (Joshi et al., 2004) and the presence of an additional two members was suggested (Liang and Joshi, 2004). Recently, six cDNAs encoding CESAs of Eucalyptus grandis were reported (Ranik and Myburg, 2006) (Figure 6). Eighteen members of the CesA family, the biggest known so far, were found in poplar or cottonwood genome where nine types of CesAs are duplicated and located on separate chromosomes (Djerbi et al., 2005; Tuskan et al., 2006). The CesA genes generally have 10-14 introns and encode proteins with 985-1088 amino acids (Richmond and Somerville, 2000). Several features are found in the amino acid sequence of the CESA proteins:

(i) Zinc-binding domain: the zinc-binding domain is located at the amino terminal region of protein and it is probably involved with the CESAs oligomerization (Figure 7) (Kurek et al., 2002). In oxidative conditions, it may be involved in the formation of homodimers and heterodimers among CESAs (Kurek et al., 2002). In this domain, there is a conserved motif called CxxC. It is located approximately $10-40$ amino acid residues downstream from the amino terminal region: $\mathrm{Cx}_{2} \mathrm{Cx}_{12} \mathrm{FxACx}_{2} \mathrm{Cx}_{2} \mathrm{PxCx}_{2} \mathrm{Cx}-\mathrm{Ex}_{5} \mathrm{Gx}_{3} \mathrm{Cx}_{2} \mathrm{C}$, where in the $\mathrm{x}$ position any amino acid could be present. Only CESAs have the motif $\mathrm{CxxC}$, a feature that distinguishes CESAs from cellulose synthase-like (CSL) proteins. In addition to the motif CxxC, sequence identity is used to help in the distinction of CESA and CSL (Richmond, 2000). A zincbinding domain-like region has been observed in CSLD members (Samuga and Joshi, 2004a);

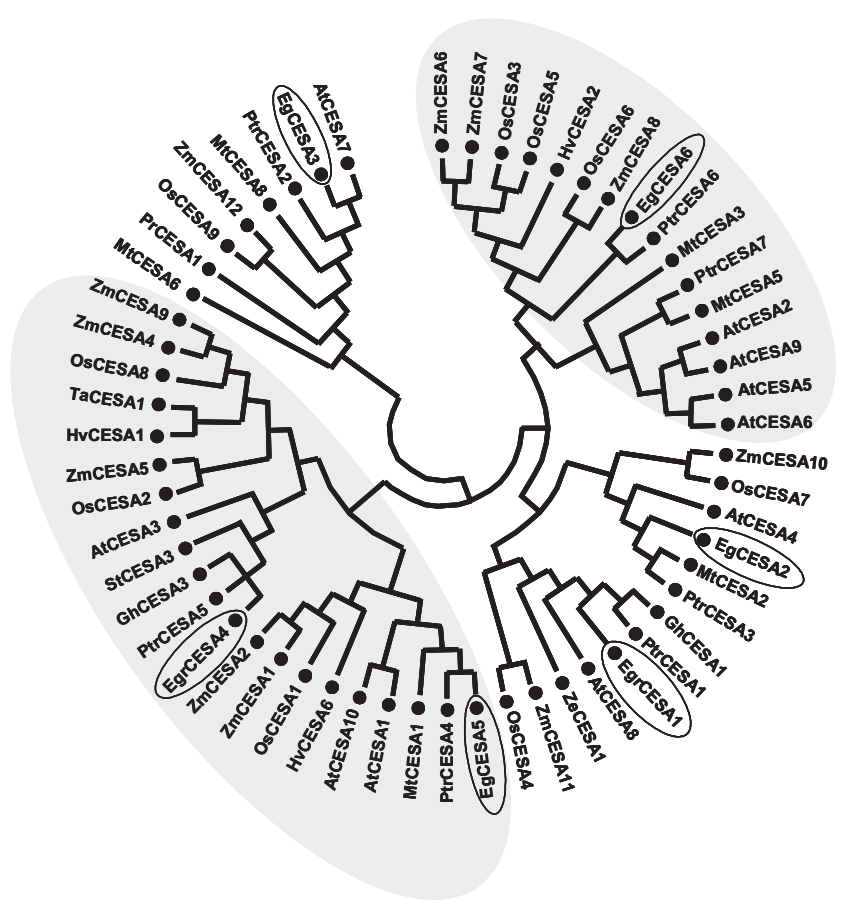

Figure 6. Tree derived from the alignment of the deduced amino acid sequences of 58 full-length CESA protein sequences. A total of 10,000 bootstrap replicates were used and only branches with at least $80 \%$ of support were considered for the development of the tree. CESAs associated with primary and secondary cell wall synthesis are respectively shown in gray and white backgrounds. The six Eucalyptus grandis CESAs are highlighted with black ellipses. Abbreviations: CESA: cellulose synthase; At: Arabidopsis thaliana; Eg: Eucalyptus grandis; Gh: Gossypium hirsutum; Hv: Hordeum vulgare; Mt: Medicago truncatula; Os: Oryza sativa; Pr: Pinus radiata; Ptr: Populus tremuloides; St: Solanum tuberosum; Ta: Triticum aestivum; Ze: Zinnia elegans; and $\mathbf{Z m}$ : Zea mays. Reprinted with permission from Ranik and Myburg (2006). Copyright (2006) Heron Publishing.

(ii) Hypervariable region I (HVRI) and II (HVRII): the HVRI and HVRII in the same species show low sequence conservation among $C e s A$ paralogs. In different species, HVRII is conserved among the CesA orthologs and it has been designated as a class specific region CSR (Vergara and Carpita, 2001; Liang and Joshi, 2004). CSR has been used to isolate cDNAs encoding CESAs because this region efficiently discriminates each member of a CesA family (Liang and Joshi, 2004; Ranik and Myburg, 2006);

(iii) Motifs indicative of processive glycosyltransferase: the CESA proteins show four motifs (D, D, D, QVLRW) 


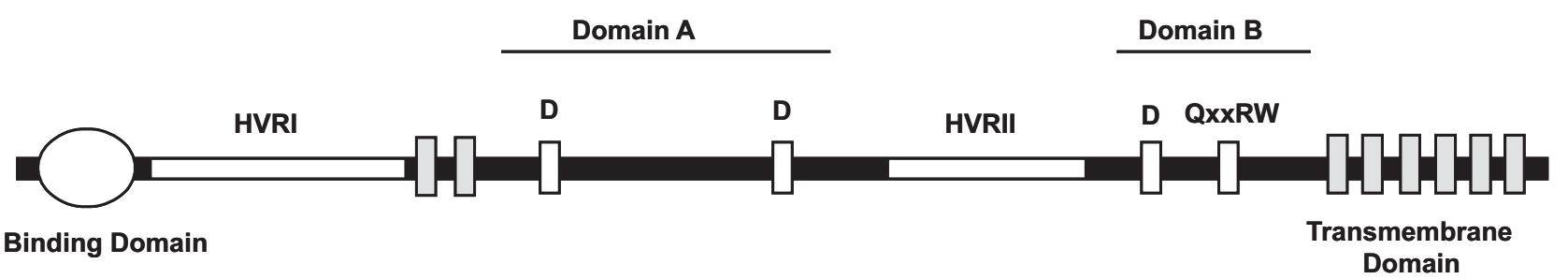

Figure 7. Schematic representation of CESA protein features. Reprinted with permission from Richmond (2000). Copyright (2006) Genome Biology.

which are essential to glycosyltransferase activity (Saxena et al., 2001). The first two D (aspartic acid) residues are located in the globular domain $\mathrm{A}$. In the globular domain B is located the third D residue and the motifQVLRW;

(iv) Globular domain A and B: the globular domains A and $\mathrm{B}$ are highly conserved among CESAs (Pear et al., 1996; Wu et al., 2000; Joshi, 2003b; Joshi et al., 2004);

(v) Transmembrane domains: CESAs show eight transmembrane domains. Two domains are located just before the beginning of the globular domain $\mathrm{A}$. The other six transmembrane domains are located just after the globular domain B, close to the carboxyl terminal region (Joshi, 2003a,b; Joshi et al., 2004).

\section{CesA GENE FAMILY IN Arabidopsis thaliana AND Populus tremuloides}

The A. thaliana genome has at least ten CesAs, denominated AtCesA1-10. There is no duplication of a functional CesA gene adjacent to any other CesAs on $A$. thaliana chromosomes. They are distributed all over the genome indicating that this is not a recent duplication event. The size of the AtCesA genes is 3.5-5.5 kb. These genes have 9-13 introns which encode proteins with 9851088 amino acid residues and its identity is variable from 53-98 \% (Richmond, 2000).

The genome of aspen has at least nine types of CesA genes: PtrCesA1 (Wu et al., 2000), PtrCesA2 (Samuga and Joshi, 2002), PtrCesA3 (Kalluri and Joshi, 2004), PtrCesA4 (Kalluri and Joshi, 2004), PtrCesA 5 (Kalluri and Joshi, 2003), PtrCesA6 (Samuga and Joshi, 2004b), and PtrCesA7 (Samuga and Joshi, 2004b) all of which encode distinct CESAs. In addition, two partial CSR regions have been isolated that are designated PtrCesA 8 and
PtrCesA9 (Liang and Joshi, 2004). These CesA genes and their encoded proteins are highly similar (>95\%) to nine types of CesAs present in the poplar genome that was completely sequenced recently (Tuskan et al., 2006). The size of the poplar CesA genes is 4.8-7.2 kb. These genes have 12-14 introns which encode proteins with 978-1096 amino acid residues and their identity varies from $64 \%$ to $76 \%$. Sequence identity analysis between orthologs of Arabidopsis and aspen CesAs reveals that PtrCesA1, PtrCesA2, PtrCesA3, PtrCesA4, PtrCesA5, PtrCesA6, and $\operatorname{PtrCesA7}$ are respective orthologs of AtCesA8, AtCesA7, AtCesA4, AtCesA1, AtCesA3, AtCesA6, and AtCesA6 (Figure 6) (Joshi et al., 2004). Thus Arabidopsis and poplars possess orthologous CesAs. All nine types of poplar CesAs are duplicated with the exception of the poplar CesA gene that is homologous to PtrCesA3 from aspen. All duplicated poplar CesA genes are distributed on different chromosomes indicating that CesA gene duplications occurred in ancient times and overall both members of duplicated genes are expressed, but in the case of secondary wall-associated aspen CesAs, one member is expressed at a much higher level than the other (C.P. Joshi, unpublished observations).

Protein sequence comparisons of higher plant CESAs reveal that all CESAs are grouped into six distinct clades which contain members associated with the primary or secondary cell wall (Figure 6) (Holland et al., 2000; Vergara and Carpita, 2001; Joshi et al., 2004; Liang and Joshi, 2004; Samuga and Joshi, 2004b; Nairn and Haselkorn, 2005; Somerville, 2006). In fact, orthologs of AtCesA1, AtCesA3, and AtCesA6 appear to be required for the synthesis of cellulose deposited in the primary cell walls (Fagard et al., 2000; Scheible et al., 2001; Burn et al., 2002; Doblin et al., 2002). In contrast, orthologs of AtCesA4, AtCesA7, and AtCesA8 seem to be essential for cellulose synthesis in the secondary cell walls (Turner and 
Somerville, 1997; Taylor et al., 1999, 2000, 2003; Zhong et al., 2003). The latter three CESA isoforms are specific to secondary cell wall formation and they actually physically interact with each other so it is highly probable that they are located in the same CelS as discussed previously (Taylor et al., 2003).

In the same way, PtrCesA1, PtrCesA2, and PtrCesA3 are involved with cellulose deposition in the secondary cell wall and PtrCesA4, PtrCesA 5, PtrCesA6, and PtrCesA7 may be involved with cellulose deposition in the primary cell wall (Joshi et al., 2004; Kalluri and Joshi, 2004; Samuga and Joshi, 2004b). The gene AtCesA 8 present in the lew2-1 mutant genome was further characterized and its disruption increases osmotic and drought stress tolerance, indicating that cellulose synthesis may be involved in stress tolerance (Chen et al., 2005), but the cause and consequence relationship needs to be delineated.

\section{THE MOST IMPORTANT UNSOLVED TOPICS IN CELLULOSE BIOSYNTHESIS}

Although some remarkable progress has been made during the past decade towards unraveling the process of cellulose biosynthesis, a number of unanswered questions still remain. In higher plants, do two distinct types of complexes of CESAs and other associated enzymes synthesize cellulose I $\alpha$ and cellulose I $\beta$ ? How is cellulose synthesized and deposited during primary and secondary cell wall formation? How is each glucose residue inverted $180^{\circ}$ with respect to its neighboring residues? Are monosaccharides or disaccharides substrates for CESAs? How are glucose chains aligned side-by-side to generate a microfibril of cellulose? How many proteins are necessary to fully assemble the CelS and synthesize cellulose? What is the exact function of each of these proteins? How are CESAs arranged in the subunits of CelS? Why are there so many CesAs in plants? Do the transmembrane helices of the CESA proteins form a pore in the plasma membrane through which the growing glucan chain can pass? Are CesAs regulated at both transcriptional and post-transcriptional phases? Would it be possible to produce wood with high contents of better cellulose and still maintain the necessary physical and mechanical properties of wood?
Would it be possible to reconstitute functional CelS in vitro that is capable of synthesizing cellulose I? What role(s) do other proteins (such as KOR) play that have been shown to affect cellulose biosynthesis in Arabidopsis mutants? Will overexpression of SUSY or other enzymes involved in photosynthetic carbon fixation improve cellulose biosynthesis? Which proteins control economically important cellulose traits such as microfibril angle, DP, and crystallinity?

In conclusion, there are still a large number of questions that need to be answered to fully understand the process of cellulose biosynthesis in plants that has direct connection with utilization of cellulose for agricultural and forest product manufacturing. The characterization of regulatory regions of CesAs genes and their transcription factors might provide insights about regulatory processes involved in the specific expression patterns of CesAs genes and consequently cellulose production.

Acknowledgments: The authors would like to acknowledge the doctoral scholarship awarded to RAFB by FAPEMIG (Minas Gerais State Research Foundation, Brazil). CPJ wishes to thank the National Science Foundation (award \# IBN-0236492), Consortium for Plant Biotechnology Research (award \# G012026-249), and the United States Department of Agriculture (award \# 200535103-15256) for supporting research in his laboratory. We would like to express our gratitude to Drs Shi-You Ding, Mike Jarvis, Todd Richmond, Martin Ranik, and Bernard Henrissat for permission to use adapted versions of the Figures shown in this review. RAFB would like to thank Professor Raimundo Santos Barros for his suggestions and criticisms of the first drafts of this manuscript.

\section{REFERENCES}

Arioli T, Peng L, Betzner AS, Burn J, Wittke W, Herth W, Camilleri C, Höfte H, Plazinski J, Birch R, Cork A, Glover J, Redmond J, Williamson RE (1998) Molecular analysis of cellulose biosynthesis in Arabidopsis. Science 279:717-720.

Bhandari S, Fujino T, Thammanagowda S, Zhang D, Xu F, Joshi CP (2006) Xylem-specific and tension stressresponsive coexpression of KORRIGAN endoglucanase and three secondary wall-associated cellulose synthase genes in aspen trees. Planta 224:828-837. 
Brett C, Waldron K (1990) Physiology and biochemistry of plant cell walls. In: Black M, Chapman J (eds), Topics in Plant Physiology, vol. 2, pp.4-57. Unwin Hyman, London.

Brown Jr RM, Saxena IM, Kudlicka K (1996) Cellulose biosynthesis in higher plants. Trends Plant Sci. 1:149156.

Brown Jr RM, Saxena IM (2000) Cellulose biosynthesis: a model for understanding the assembly of biopolymers. Plant Physiol. Biochem. 38:57-67.

Burn JE, Hocart CH, Birch RJ, Cork AC, Williamson RE (2002) Functional analysis of the cellulose synthase genes CesA1, CesA2, and CesA3 in Arabidopsis. Plant Physiol. 129:797-807.

Burton RA, Shirley NJ, King BJ, Harvey AJ, Fincher GB (2004) The CesA gene family of barley. Quantitative analysis of transcripts reveals two groups of coexpressed genes. Plant Physiol. 134:224-236.

Chen Z, Hong X, Zhang H, Wang Y, Li X, Zhu JK, Gong Z (2005) Disruption of the cellulose synthase gene, AtCesA8/IRX1, enhances drought and osmotic stress tolerance in Arabidopsis. Plant J. 43:273-283.

Delmer DP, Amor Y (1995) Cellulose biosynthesis. Plant Cell 7:987-1000.

Delmer DP (1999) Cellulose biosynthesis: exciting times for a difficult field of study. Annu. Rev. Plant Physiol. Plant Mol. Biol. 50:245-276.

Delmer DP, Haigler CH (2002) The regulation of metabolic flux to cellulose, a major sink for carbon in plants. Metab. Eng. 4:22-28.

Ding SY, Himmel ME (2006) The maize primary cell wall microfibril: a new model derived from direct visualization. J. Agric. Food Chem. 54:597-606.

Djerbi S, Lindskog M, Arvestad L, Sterky F, Teeri TT (2005) The genome sequence of Black Cottonwood (Populus trichocarpa) reveals 18 conserved cellulose synthase (CesA) genes. Planta 221:739-746.

Doblin MS, Kurek I, Jacob-Wilk D, Delmer DP (2002) Cellulose biosynthesis in plants: from genes to rosettes. Plant Cell Physiol. 43:1407-1420.

Eckardt NA (2003) Cellulose synthesis takes the CesA train. Plant Cell 15:1685-1687.

Fagard M, Desnos T, Desprez T, Goubet F, Refrégier G, Mouille G, McCann M, Rayon C, Vernhettes S, Höfte H (2000) PROCUSTE1 encodes a cellulose synthase required for normal cell elongation specifically in roots and dark-grown hypocotyls of Arabidopsis. Plant Cell 12:2409-2423.

Gomide JL, Colodette JL, de Oliveira RC, Silva CM (2005)
Caracterização tecnológica, para produção de celulose, da nova geração de clones de Eucalyptus do Brasil. Rev. Árv. 29:129-137.

Haigler CH, Brown Jr RM (1986) Transport of rosettes from the Golgi apparatus to the plasma membrane in isolated mesophyll cells of Zinnia elegans during differentiation to tracheary elements in suspension culture. Protoplasma 134:111-120.

Haigler CH, Ivanova-Datcheva M, Hogan PS, Salnikov VV, Hwang S, Martin K, Delmer DP (2001) Carbon partitioning to cellulose synthesis. Plant Mol. Biol. 47:29-51.

Hardy BJ, Sarko A (1996) Molecular dynamics simulations and diffraction-based analysis of the native cellulose fiber: structural modeling of the I- $\alpha$ and I- $\beta$ phases and their interconversion. Polymer 37:1833-1839.

Holland N, Holland D, Helentjaris T, Dhugga KS, Xoconostle-Cazares B, Delmer DP (2000) A comparative analysis of the plant cellulose synthase (CesA) gene family. Plant Physiol. 123:1313-1323.

Jarvis M. 2003. Cellulose stacks up. Nature 426:611-612.

Joshi CP (2003a) Xylem-specific and tension stress responsive expression of cellulose synthase genes from aspen trees. Appl. Biochem. Biotechnol. 105:17-26.

Joshi CP (2003b) Molecular biology of cellulose biosynthesis in plants. In: Pandalai S (ed), Recent Research Development in Plant Molecular Biology, vol. 1, pp.19-38. Research Signpost Press, Kerala.

Joshi CP, Bhandari S, Ranjan P, Kalluri UC, Liang X, Fujino T, Samuga A (2004) Genomics of cellulose biosynthesis in poplars. New Phytol. 164:53-61.

Kalluri UC, Joshi CP (2003) Isolation and characterization of a new, full-length cellulose synthase cDNA, PtrCESA5 from developing xylem of aspen trees. J. Exp. Bot. 54:2187-2188.

Kalluri UC, Joshi CP (2004) Differential expression patterns of two cellulose synthase genes are associated with primary and secondary cell wall development in aspen trees. Planta 220:47-55.

Kimura S, Laosinchai W, Itoh T, Cui X, Linder CR, Brown Jr RM (1999) Immunogold labeling of rosette terminal cellulose-synthesizing complexes in the vascular plant Vigna angularis. Plant Cell 11:2075-2085.

Kono H, Yunoki S, Shikano T, Fujiwara M, Erata T, Kawai $\mathrm{M}$ (2002) CP/MAS ${ }^{13} \mathrm{C}$ NMR study of cellulose and cellulose derivatives. 1 . Complete assignment of the $\mathrm{CP} / \mathrm{MAS}{ }^{13} \mathrm{C}$ NMR spectrum of the native cellulose. J. Am. Chem. Soc. 124:7506-7511.

Koyama M, Helbert W, Imai T, Sugiyama J, Henrissat B (1997) Parallel-up structure evidences the molecular 
directionality during biosynthesis of bacterial cellulose. Proc. Natl. Acad. Sci. USA 94:9091-9095.

Kurek I, Kawagoe Y, Jacob-Wilk D, Doblin M, Delmer D (2002) Dimerization of cotton fiber cellulose synthase catalytic subunits occurs via oxidation of the zincbinding domains. Proc. Natl. Acad. Sci. USA 99:1110911114.

Langan P, Nishiyama Y, Chanzy H (2001) X-ray structure of mercerized cellulose II at $1 \AA$ resolution. Biomacromolecules 2:410-416.

Liang X, Joshi CP (2004) Molecular cloning of ten distinct hypervariable regions from cellulose synthase gene superfamily in aspen trees. Tree Physiol. 24:543-550.

Mellerowicz EJ, Baucher M, Sundberg B, Boerjan W (2001) Unraveling cell wall formation in the woody dicot stem. Plant Mol. Biol. 47:239-274.

Molhoj M, Pagant S, Hofte H (2002) Towards understanding the role of membrane bound endo- $\beta$ glucanases in cellulose biosynthesis. Plant Cell Physiol. 43:1399-1406.

Mueller SC, Brown Jr RM (1980) Evidence for an intramembrane component associated with a cellulose microfibril synthesizing complex in higher plants. J. Cell Biol. 84:315-326.

Nairn CJ, Haselkorn T (2005) Three loblolly pine CesA genes expressed in developing xylem are orthologous to secondary cell wall CesA genes of angiosperms. New Phytol. 166:907-915.

Nishiyama Y, Langan P, Chanzy H (2002) Crystal structure and hydrogen-bonding system in cellulose I $\beta$ from synchrotron X-ray and neutron fiber diffraction. J. Am. Chem. Soc. 124:9074-9082.

Nishiyama Y, Sugiyama J, Chanzy H, Langan P (2003) Crystal structure and hydrogen bonding system in cellulose I alpha from synchrotron X-ray and neutron fiber diffraction. J. Am. Chem. Soc. 125:14300-14306.

O'Sullivan AC (1997) Cellulose: the structure slowly unravels. Cellulose 4:173-207.

Pear JR, Kawagoe Y, Schreckengost WE, Delmer DP, Stalker DM (1996) Higher plants contain homologs of the bacterial CelA genes encoding the catalytic sub-unit of cellulose synthase. Proc. Natl. Acad. Sci. USA 93:12637-12642.

Perrin RM (2001) Cellulose: how many cellulose synthases to make a plant? Curr. Biol. 11:213-216.

Pilate G, Déjardin A, Laurans F, Leplé JC (2004) Tension wood as a model for functional genomics of wood formation. New Phytol. 164:63-72.

Ranik M, Myburg AA (2006) Six new cellulose synthase genes from Eucalyptus are associated with primary and secondary cell wall biosynthesis. Tree Physiol. 26:545556.

Read SM, Bacic T (2002) Prime time for cellulose. Science 295:59-60.

Richmond TA (2000) Higher plant cellulose synthases. Genome Biol. 1:3001.1-3001.6.

Richmond TA, Somerville CR (2000) The cellulose synthase superfamily. Plant Physiol. 124:495-498.

Robert S, Bichet A, Grandjean O, Kierzkowski D, SatiatJeunemattre B, Pelletier S, Hauser MT, Hofte H, Vernhettes S (2005) An Arabidopsis endo-1,4- $\beta$-Dglucanase involved in cellulose synthesis undergoes regulated intracellular cycling. Plant Cell 17:3378-3389.

Rowland SP, Howley PS (1988) Hydrogen bonding on accessible surfaces of cellulose from various sources and relationship to order within crystalline regions. J. Polym. Sci., Part A: Polym. Chem. 26:1769-1778.

Samuga A, Joshi CP (2002) A new cellulose synthase gene (PtrCesA2) from aspen xylem is orthologous to Arabidopsis AtCesA7 (irx3) gene associated with secondary cell wall synthesis. Gene 296:37-44.

Samuga A, Joshi CP (2004a) Cloning and characterization of cellulose synthase-like gene, PtrCSLD2 from developing xylem of aspen trees. Physiol. Plant. 120:641651.

Samuga A, Joshi CP (2004b) Expression patterns of two primary cell wall-related cellulose synthase cDNAs, PtrCESA6 and PtrCESA7 from aspen. Gene 334:71-80.

Saxena IM, Lin FC, Brown Jr RM (1990) Cloning and sequencing of the cellulose synthase catalytic sub-unit gene of Acetobacter xylinum. Plant Mol. Biol. 15:673683.

Saxena IM, Brown Jr RM (1995) Identification of a second cellulose synthase gene (acsAII) in Acetobacter xylinum. J. Bacteriol. 177:5276-5283.

Saxena IM, Brown Jr RM, Dandekar T (2001) Structurefunction characterization of cellulose synthase: relationship to other glycosyltransferases. Phytochemistry 57:1135-1148.

Saxena IM, Brown Jr RM (2005) Cellulose biosynthesis: current views and evolving concepts. Ann. Bot. 96:9-21.

Scheible WR, Eshed R, Richmond T, Delmer D, Somerville C (2001) Modifications of cellulose synthase confer resistance to isoxaben and thiazolidinone herbicides in Arabidopsis ixrl mutants. Proc. Natl. Acad. Sci. USA 98:10079-10084.

Somerville CR (2006) Cellulose synthesis in higher plants. Annu. Rev. Cell Dev. Biol. 22:53-78.

Sturcova A, His I, Apperley DC, Sugiyama J, Jarvis MC (2004) Structural details of crystalline cellulose from higher plants. Biomacromolecules 5:1333-1339. 
Tanaka K, Murata K, Yamazaki M, Onosato K, Miyao A, Hirochika H (2003) Three distinct rice cellulose synthase catalytic subunit genes required for cellulose synthesis in the secondary wall. Plant Physiol. 133:73-83.

Taylor NG, Laurie S, Turner SR (2000) Multiple cellulose synthase catalytic subunits are required for cellulose synthesis in Arabidopsis. Plant Cell 12:2529-2540.

Taylor NG, Scheible WR, Cutler S, Somerville CR, Turner SR (1999) The irregular xylem3 locus of Arabidopsis encodes a cellulose synthase required for secondary cell wall synthesis. Plant Cell 11:769-780.

Taylor NG, Howells RM, Huttly AK, Vickers K, Turner SR (2003) Interactions among three distinct CESA proteins essential for cellulose synthesis. Proc. Natl. Acad. Sci. USA 100:1450-1455.

Timell TE (1969) The chemical composition of tension wood. Svensk Papperstidning 72:173-181.

Tsekos I (1999) The sites of cellulose synthesis in algae: diversity and evolution of cellulose-synthesizing enzyme complexes. J. Phycol. 35:635-655.

Tsekos I, Orolagas N, Herth W (1999) Cellulose microfibril assembly and orientation in some bangiophyte red algae: relationship between synthesizing terminal complexes and microfibril structure, shape, and dimensions. Phycologia 38:217-224.

Turner SR, Somerville CR (1997) Collapsed xylem phenotype of Arabidopsis identifies mutants deficient in cellulose deposition in the secondary cell wall. Plant Cell 9:689-701.

Tuskan GA et al. (2006) The genome of western black cottonwood, Populus trichocarpa (Torr. \& Gray ex Brayshaw). Science 313:1596-1604.

Vergara CE, Carpita NC (2001) $\beta$-D-Glycan synthases and the CesA gene family: lessons to be learned from the mixed-linkage $(1 \rightarrow 3),(1 \rightarrow 4) \beta$-D-glucan synthase. Plant Mol. Biol. 47:145-160.

Wada MJ (2002) Lateral thermal expansion of cellulose I $\beta$ and IIII polymorphs. J. Polym. Sci., Part B: Polym. Phys. 40:1095-1102.

Wong HC, Fear AL, Calhoon RD, Eichinger GH, Mayer R, Amikam D, Benziman M, Gelfand DH, Meade JH, Emerick AW, Bruner R, Ben-Bassat A, Tal R (1990) Genetic organization of the cellulose synthase operon in Acetobacter xylinum. Proc. Natl. Acad. Sci. USA 87:8130-8134.

Wu L, Joshi CP, Chiang VL (2000) A xylem-specific cellulose synthase gene from aspen (Populus tremuloides) is responsive to mechanical stress. Plant J. 22:495-502.

Zhong R, Morrison WH, Freshour GD, Hahn MG, Ye ZH (2003) Expression of a mutant form of cellulose synthase AtCesA 7 causes dominant negative effect on cellulose biosynthesis. Plant Physiol. 132:786-795. 